\title{
Mapeamento de competências do bibliotecário para uma atuação na indústria
}

\author{
Mapping the librarian's skills for industry performance \\ Vanessa Silva Araújo ${ }^{1}$, Danielly Oliveira Inomata ${ }^{2}$ \\ ${ }^{1}$ Universidade Federal do Amazonas (UFAM), Manaus, AM, Brasil. ORCID: https://orcid.org/0000-0001-6267-2628 \\ 2 Universidade Federal do Amazonas (UFAM), Manaus, AM, Brasil. ORCID: https://orcid.org/0000-0001-5657-2137
}

Autor para correspondência/Mail to: Danielly Oliveira Inomata, inomata.danielly@gmail.com

Recebido/Submitted: 08 de março de 2021; Aceito/Approved: 13 de maio de 2021

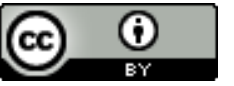

Copyright (c) 2021 Araújo \& Inomata. Todo o conteúdo da Revista (incluindo-se instruções, política editorial e modelos) está sob uma licença Creative Commons Atribuição 4.0 Internacional. Ao serem publicados por esta Revista, os artigos são de livre uso em ambientes educacionais, de pesquisa e não comerciais, com atribuição de autoria obrigatória. Mais informações em http://revistas.ufpr.br/atoz/about/submissions\#copyrightNotice.

\begin{abstract}
Resumo
Introdução: apresenta a investigação sobre as competências necessárias para a atuação do bibliotecário na indústria, as quais foram identificadas na literatura, servindo como base para a pesquisa de campo realizada em uma indústria do Pólo Industrial de Manaus, e posteriormente validadas por especialistas no assunto. Método: a pesquisa caracteriza-se por ser exploratória, descritiva, de natureza qualitativa, na qual a pesquisa bibliográfica fundamentou a pesquisa de campo, cujos dados foram coletados por meio de formulário eletrônico. Resultados: foram identificadas as competências necessárias para a atuação do bibliotecário na indústria, verificando-se que as competências propostas a partir da literatura estão de acordo com a atuação do bibliotecário no campo de atuação. Das competências identificadas, as mais relevantes são conhecimentos sobre gestão, habilidades relacionadas às capacidades de comunicação e trabalho em equipe, atitudes relacionadas à ser ético e ser proativo. Conclusão: concluiu-se que há a necessidade de bibliotecários na indústria para lidar com a informação neste ambiente, sendo que as competências identificadas orientam esta atuação, garantindo melhor desempenho nas atividades da indústria.

Metodologia: foi utilizada a metodologia ProKnow-C para a construção do conhecimento e a pesquisa foi realizada na base de dados Scopus, na qual foram encontrados 566 artigos com os critérios de busca utilizados, dos quais 221 foram selecionados por estarem alinhados aos objetivos da pesquisa. Aplicando os critérios de seleção e exclusão definidos previamente, 41 estudos compuseram este portfólio bibliográfico. Resultados: a análise bibliométrica evidenciou a heterogeneidade de autores e a concentração de pesquisas nos Estados Unidos e Europa. Conclusão: com este portfólio, recomenda-se a averiguação das possibilidades de criação de experiências de envolvimento profundo com consumidores nas práticas de marketing e publicidade, em especial com o uso da tecnologia da Realidade Virtual, gerando o marketing de experiência.
\end{abstract}

Palavras-chave: Profissional da informação; Mapeamento de competências; Informação para indústria; Competências do bibliotecário.

\begin{abstract}
Introduction: presents the investigation on the competencies necessary for the librarian's performance in the industry, which were identified in the literature, serving as a basis for the field research carried out in an industry of the Industrial Pole of Manaus, and later validated by specialists in the subject. Method: the research is exploratory, descriptive, of qualitative nature, in which the bibliographic research supported the field research, whose data were collected through an electronic form. Results: it identifies the necessary competencies for the librarian's performance in the industry, verifying that the competencies proposed from the literature are following the librarian's performance in the field. Of the competencies identified, the most relevant are knowledge about management, skills related to communication and teamwork skills, attitudes related to being ethical and being proactive. Conclusions: it concludes that there is a need for librarians in the industry to deal with information in this environment, and the identified skills guide this performance, ensuring better performance in the industry's activities.
\end{abstract}

Keywords: Information professional; Skills mapping; Industry information; Librarian skills.

\section{INTRODUÇÃO}

Tradicionalmente, a atuação do bibliotecário esteve vinculada ao ambiente da biblioteca, desempenhando atividades de organização e armazenamento de livros, cuidando da integridade de tais materiais informacionais, os quais eram restritos a uma minoria da população. Esta percepção do bibliotecário foi mudando ao longo do tempo e novas funções foram sendo atribuídas a este profissional, que numa sociedade contemporânea pode atuar nos mais diversos setores da sociedade, como editoras, empresas, emissoras de televisão e indústrias.

Estes novos espaços de atuação são decorrentes da evolução das Tecnologias da Informação e Comunicação (TICs), que afetaram as rotinas de trabalho e as necessidades de informação em muitas esferas da sociedade, favorecendo o surgimento de ferramentas de recuperação de informações, consequentemente a exigência de um profissional com domínio para utilizá-las.

A indústria, foco deste trabalho, caracteriza-se por ser um conjunto de atividades econômicas para a produção de bens para a comercialização. Neste espaço há a manipulação de informações técnicas e tecnológicas, as quais são imprescindíveis para a realização das atividades executadas no meio industrial. 
Na Região Norte do Brasil, especificamente em Manaus, encontra-se o Pólo Industrial, que representa um grande potencial de mercado para o bibliotecário, em especial aqueles formados no curso de Biblioteconomia da Universidade Federal do Amazonas (UFAM). A pesquisa se desenvolveu a partir de um movimento de antecipação à demanda por profissionais da informação na indústria, para isso buscou-se conhecer as competências do bibliotecário na indústria, um campo latente para a atuação deste profissional, caracterizando a informação utilizada neste ambiente, a qual se apresenta de maneira diferente dos ambientes tradicionais de empregabilidade, com vistas a compreender quais são as competências demandadas pela indústria, a partir do mapeamento de conhecimentos, habilidades e atitudes relativas a esta atuação.

\section{O PROFISSIONAL DA INFORMAÇÃO: CARACTERÍSTICAS DO BIBLIOTECÁRIO}

De acordo com a Classificação Brasileira de Ocupações [CBO] (2002), o bibliotecário caracteriza-se como um profissional da informação que disponibiliza para o uso informações que se encontrem nos mais variados suportes. O profissional pode atuar em qualquer local onde há informação, desde as tradicionais bibliotecas, até setores do comércio, indústria e serviços (CBO (2002). O Conselho Federal de Biblioteconomia (CFB) atesta no art. $3^{\circ}$ do Código de Ética e Deontologia do Bibliotecário brasileiro que:

A atuação do bibliotecário fundamenta-se no conhecimento da missão, objetivos, áreas de atuação e perfil sociocultural do público alvo da instituição onde está instalada a unidade de informação em que atua, bem como das necessidades e demandas dos usuários, tendo em vista o desenvolvimento dos indivíduos e da sociedade (Resolução CFB n ${ }^{\circ}$ 207, (2018, p.1).

Segundo Valls (2019), os bibliotecários são profissionais formados em Biblioteconomia, podendo aperfeiçoar suas competências em outras áreas do conhecimento diante das necessidades profissionais; ou são profissionais de outras áreas que buscam a Biblioteconomia para complementar sua formação, de forma que possam atuar em ambientes especializados.

A respeito dos espaços não tradicionais de atuação do bibliotecário, Valls (2019) discorre sobre a postura que este profissional deve ter diante destes novos campos:
[...] diferente do espaço tradicional, o bibliotecário fora das bibliotecas precisa conquistar espaços.
Não existem plaquinhas na porta dizendo "aqui há vagas", porém muitas vezes existem placas imensas dizendo "precisamos de alguém que nos ajude a organizar o caos informacional, socorro!!", e aí, os bibliotecários competentes podem se aventurar. Digo bibliotecários competentes (no contexto das competências, ou seja, conhecimentos, habilidades, atitudes e valores), porque esses novos espaços de atuação exigem do bibliotecário conhecimentos e habilidades além das desenvolvidas na graduação.

Como visto, o bibliotecário adquire competências básicas durante a formação que o capacitam para a atuação em unidades de informação, mas deve adquirir novas competências, de acordo com o lugar onde pretende atuar, adequando-se ao ambiente informacional. Efeitos da globalização, das constantes mudanças, do processo de competitividade nas organizações e no mercado, a presença do bibliotecário pode ser uma alternativa protagonista, mas este profissional precisa ter um diferencial que o destaque dos demais, seja na busca por conhecimentos especializados, seja na educação continuada e domínio de outros idiomas.

Para Orelo e da Cunha (2013), o bibliotecário deve ter, primordialmente, competência informacional, isto é, a capacidade de identificar as necessidades de informação, ter conhecimento sobre as fontes de informação e saber como recuperar as informações, culminando no bom uso destas. Adicionalmente, no que se refere a ambientes especializados é fundamental ter conhecimentos sobre os assuntos para os quais esse local é voltado, porquanto isso permite que bibliotecários e usuários possam dialogar, uma vez que este profissional passa a dispor de um domínio sobre a informação, tornando-se especialista no assunto. Ademais, "[...] deve ter além de conhecimentos de processamento técnico e de mediação da informação, um perfil dinâmico, com domínio das tecnologias, habilidades de gestão da informação e preocupar-se com a educação continuada, o que remete à competência informacional". (Orelo \& da Cunha, 2013, p.28).

Isso mostra que o bibliotecário, considerando-se a amplitude de sua formação, é um profissional com capacidade para adaptar-se aos novos ambientes, podendo contribuir com o desenvolvimento das atividades organizacionais, visto que possui qualidades para tal. É um profissional com perfil dinâmico para atuar em diversos locais.

\section{INFORMAÇÃO PARA INDÚSTRIA}

A indústria caracteriza-se por ser um conjunto de atividades econômicas que visa a produção de bens de consumo. Neste âmbito também ocorre o processamento de informações, as quais auxiliam nas atividades cotidianas deste setor. Como destaca Silva (2016, p.306), "A informação constitui-se como princípio basilar nas atividades das organizações" cujo valor agregado é concernente à sua circulação interna ou externa à tomada de decisão. Para Pinheiro (1991, p.17), a questão da informação para a indústria é sedimentada em dois pilares fundamentais: 
[...] a utilização, pelas pequenas e médias indústrias, de serviços de informação exógenos, sediados em institutos de pesquisa e de prestação de serviços para o setor produtivo, em federações de indústrias, dentre outras entidades; - os serviços de informação para a indústria devem possuir características de centros de análise da informação, tendo em vista que, para o efetivo atendimento às pequenas e médias indústrias, torna-se necessária a reelaboração das informações, adequando-as, na forma e na linguagem, ao nível da assimilação técnica desses usuários. Pode-se afirmar então que a informação para a indústria deve-se constituir em um artigo processado, e não em uma matéria-prima. Dessa forma, quando a informação a ser fornecida para a indústria, além de ser específica, embute na sua elaboração (ou reelaboração) atividades de análise e interpretação, é denominada de "informação com valor agregado".

Segundo Fyre (1973, p.177), o bom desempenho de uma empresa é proveniente de capital, tecnologia e recursos humanos e, se apoiados na informação, espera-se que haja maior eficácia destes elementos. (2016, p.307) salienta a importância do processo de comunicação da informação dentro da indústria, a qual "[...] visa aproximar as informações consideradas essenciais ao desempenho das atividades de qualquer indivíduo".

A indústria é um local onde são realizadas atividades que demandam informações de caráter científico, tecnológico, estratégico para negócios, comercial, econômico-financeiro, regulamentar e jurídico, ambiental e de segurança, que segundo Battaglia (1999) (como citado em Damasio e Longo (2002, p.14)) "formam a base de conhecimento utilizada para a tomada de decisão nas empresas". Fyre (1973) já sinalizava que essas informações podem ser encontradas nos mais diversos suportes, como catálogos técnicos, patentes, documentos de conferência, dentre outros. Ou mesmo em bibliotecas corporativas, como ressaltaram Hansen e Curtis (1998), esclarecendo que a biblioteca corporativa deve ter em seu acervo materiais que satisfaçam as necessidades de informação mais frequentes dos usuários, tais quais livros, obras de referência, revistas acadêmicas, publicações comerciais, normas, patentes, serviços online e recursos da internet.

A relevância da informação para todas as organizações é evidente por estar presente em todas as suas atividades. Vale destacar que a indústria gera produtos para a sociedade, o que demanda informações precisas cuja busca deve ser executada por profissionais qualificados, como o bibliotecário. Segundo Silva et al. (2008, p.73), é possível observar uma "[...] necessidade urgente e crescente das indústrias em adquirir, organizar e disseminar informações e conhecimento, isto é, investir na estruturação dos seus sistemas de gestão de informação, conhecimento e inovação". Ao mesmo tempo que carece de ampliar a visão do próprio bibliotecário para novos campos de atuação, como por exemplo, o contexto da indústria. Além de caracterizar-se por ser tecnológica e para negócios, a informação para a indústria deve também ser atualizada. Assim como em outros setores, as demandas por informação no setor industrial devem ser supridas de maneira imediata e precisa, a qual é utilizada para a tomada de decisão, para a solução de problemas, para o desenvolvimento e comercialização de produtos, ou mesmo para ações pontuais relacionadas às atividades do cotidiano da organização.

A informação é estritamente valorosa, visto que sua utilização pode agregar valor comercial à indústria que se apropria dela, proporcionando o desenvolvimento de novos produtos e aumentando a geração de lucros. Como destacado por Damasio \& Longo (2002, p.13-14):

O setor produtivo necessita de informações além daquelas tradicionalmente fornecidas pelos sistemas de bibliotecas com fins educativos, e outros como o de lazer. Ele necessita daquelas que possuem valor comercial e que possibilitam maximizar os processos de produção ou viabilizar o seu desenvolvimento, cujas informações, de natureza variada, são caracterizadas em diferentes tipos: científica, tecnológica, estratégica e de negócios [...].

Segundo Bexon, Stephens, e Pritchett (2002), ao reunir informações sobre os concorrentes e o ambiente externo da empresa, a organização pode melhorar seu desempenho, visto que a inteligência competitiva permite a análise das atividades dos concorrentes e das tendências de negócios, ajudando a organização na tomada de decisões. Estes elementos acentuam a necessidade de um profissional capacitado para lidar com a informação no setor industrial.

Ottonicar e Valentim (2019, p.2) destacam que, em função da mudança de paradigma que nos trouxe a Indústria 4.0 (I4.0), que transformou os meios de produção e modo de trabalho nas organizações, requer que "cada vez mais as organizações necessitam de pessoas competentes em informação, devido a produção massiva de dados e informação da I4.0". Nesta perspectiva, os colaboradores da indústria, nos seus diferentes setores, podem desenvolver novas formas de aprendizagem e aplicar em seu cotidiano organizacional.

\section{A TRÍADE DA COMPETÊNCIA: CONHECIMENTOS, HABILIDADES E ATITUDES (CHA)}

Competência é qualificador para atuação profissional, a qual pode garantir exitoso desempenho no exercício de atividades, bem como fluído funcionamento da organização. Amaral, Garcia, Faria, e Aliprandini (2008, p.8) entendem que competência é: 
[...] o termo utilizado para qualificar a pessoa apta a realizar, no presente, sua atividade com maestria, tendo, para tanto, suficientes conhecimentos, habilidades e atitudes. Essa definição trata a competência como um termo amplo, composto por aspectos intelectuais, emocionais e morais, sendo todos importantes para o desempenho adequado das funções, nas quais o profissional é dito competente.

Cazella, Behar, Schneider, da Silva, e Freitas (2012) destacam que as "competências são formadas por um conjunto de elementos, a saber: Conhecimentos, Habilidades e Atitudes (CHA)." Pintro, Rados, e Inomata (2017, p.333) ilustram estes elementos que compõem a tríade denominada CHA, como exposto na Figura 1, que formam as três dimensões da competência.

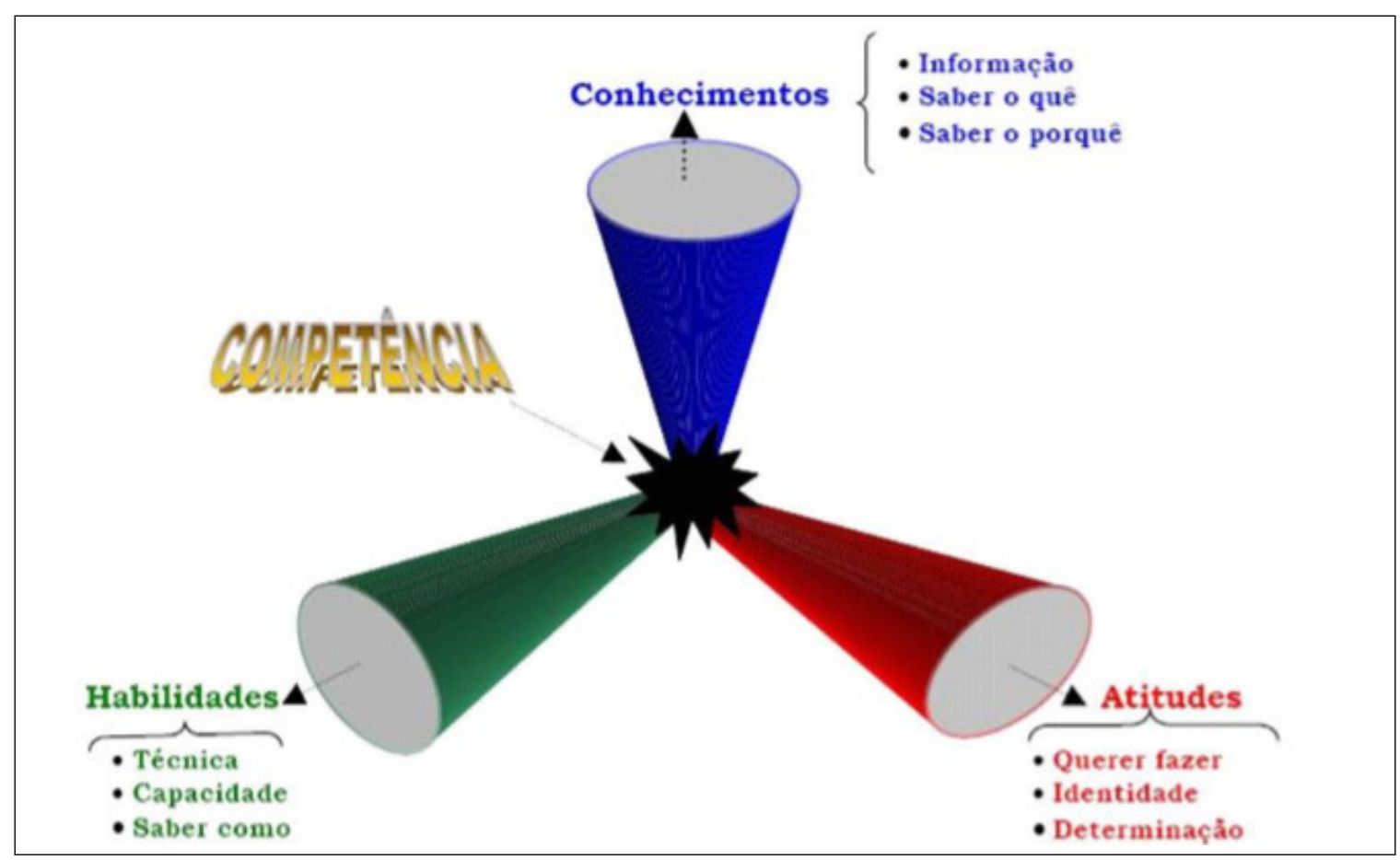

Figura 1. As três dimensões da competência Fonte: Recuperado de "Competências do bibliotecário no processo de referência educativo de bibliotecas universitárias” de S. Pintro, G. Varvakis \& D. O. Inomata, 2017, Revista ACB: Biblioteconomia em Santa Catarina 22.

Evidencia-se que os conhecimentos são aqueles adquiridos ao longo do tempo; as habilidades são o ato de colocar em práticas estes conhecimentos adquiridos; e as atitudes competem aos aspectos sociais do trabalho (Amorim \& Amaral, 2011). Para melhor compreensão, destaca-se que o conhecimento e a habilidade são relacionados aos aspectos técnicos, sendo a atitude um aspecto comportamental.

Dutra (2017, p.15) considera que compreender as competências por meio do CHA é um enfoque "pouco instrumental, uma vez que o fato das pessoas possuírem determinado conjunto de conhecimentos, habilidades e atitudes, não é garantia que elas agregarão valor para a organização", é necessário além disso é necessário ter a capacidade de entrega para a organização, tanto relacionadas ao trabalho como as suas realizações pessoais.

No processo de formação de um profissional, ou seja, quando está na graduação, os aspectos técnicos estão relacionados aos conteúdos programáticos das disciplinas, que são de cunho teórico e prático. Quanto aos aspectos comportamentais (atitudes), estes são intrínsecos ao indivíduo, sem obrigatoriedade de serem desenvolvidos no processo formativo regular, exatamente por serem particulares.

A American Library Association (ALA) (2009) lista as competências essenciais do bibliotecário, separando estas competências em oito categorias, a saber: fundamentos da profissão, recursos de informação, organização de conhecimentos e informações registradas, conhecimentos e habilidades tecnológicas, serviços de referência e usuários, pesquisa, educação continuada e administração e gestão. Ainda de acordo com a ALA, o bibliotecário deve ter competências além das listadas em cada categoria, sendo necessário possuir conhecimento especializado na sua área de atuação, seja em um contexto acadêmico, escolar, ou nas áreas emergentes, como a indústria.

Adiciona-se outros aspectos como a criatividade e a ética. No contexto da criatividade nas organizações, Jerônimo et al. (2015, p.16) destaca que "[...] só recentemente as organizações começaram a perceber criatividade, pensamento inovador e espírito empreendedor como competências essenciais para a competitividade [...]". A autora expõe ainda que a criatividade e a inovação podem aumentar a vantagem competitiva das organizações, bem como constituir benefícios para o profissional e para a sociedade. A ética é vista por Pizarro (2011) como fundamental nas organizações, uma vez que são ambientes competitivos e com vistas a produtividade econômica, devendo o bibliotecário avaliar o impacto da informação dentro das organizações. 
Ademais, sobre a questão ética no contexto da I4.0, Ottonicar e Valentim (2019, p.15), reforçam que "a ética no ambiente de negócios é fundamental, pois o armazenamento de dados em sistemas e nas nuvens podem ser facilmente haqueados por concorrentes desleais".

Estas características podem servir como base para a atuação do bibliotecário na indústria, orientando o desempenho de suas funções como profissional da informação dentro deste ambiente mutável, turbulento e competitivo, em que os modos de produção são cada vez mais associados à informação e ao conhecimento.

\section{METODOLOGIA}

A pesquisa caracteriza-se como exploratória e descritiva, visto que identifica, analisa e discorre sobre as competências do bibliotecário por meio da ferramenta CHA. Quanto à abordagem é qualitativa, realizada por meio do mapeamento das competências necessárias para o bibliotecário atuar na indústria, inicialmente por meio da revisão de literatura, seguido de entrevista exploratória com um bibliotecário que atuou na indústria, um gerente de RH e com um colaborador de uma indústria de médio porte, que serviram para calibrar o quadro de competências, seguidamente validado por especialistas (bibliotecários), quanto ao grau de relevância e concordância. Em suma, ocorreu por meio de três etapas:

Etapa 1. Consiste na identificação de competências, sendo realizado um levantamento bibliográfico em duas bases de dados, sendo uma nacional, a Base de Dados em Ciência da Informação - BRAPCI e uma base de dados internacional, a Scopus, utilizando como descritores de busca "Profissional da informação" AND Indústria na BRAPCI e "Information professional" AND Industry na Scopus. A seleção dos artigos relevantes se deu por meio da leitura dos títulos e resumos, sendo selecionados 27 documentos que serviram de base para introduzir os conceitos, as competências e o contexto da atuação do bibliotecário na indústria. Adicionalmente, optou-se por buscar os artigos citados nas referências dos textos mais relevantes, buscando verificar na literatura as competências que são requisitadas do profissional da informação pela indústria.

Etapa 2. Mapeamento das competências no campo. A entrevista exploratória foi a estratégia utilizada para conhecer a prática profissional na ambiência da indústria, sendo utilizado um Roteiro de Entrevista com quatro perguntas abertas iniciais, permitindo que informações adicionais pudessem emergir de forma orgânica, participou desta ação um bibliotecário atuante na indústria em Manaus. Na indústria utilizou-se um Protocolo de Entrevista, o qual foi encaminhado por e-mail para o gerente de Recursos Humanos e o colaborador, a fim de verificar sua percepção sobre o profissional da informação na indústria.

Etapa 3. Validação das competências. Listaram-se as competências encontradas na literatura e no campo, condensadas em um Instrumento Eletrônico de Avaliação, o qual foi encaminhado para 14 profissionais especialistas, selecionados a partir da identificação na literatura como autores de artigo sobre o tema, bem como dos currículos via plataforma Lattes, dentre os quais estavam bibliotecários que já atuaram na indústria e pesquisadores sobre áreas emergentes da Biblioteconomia, para verificar o grau de concordância destes especialistas em relação às competências propostas para a atuação do bibliotecário na indústria. Destes, nove aceitaram participar desta etapa da pesquisa.

\section{RESULTADOS}

A partir da literatura foram identificadas Competências, relativas aos Conhecimentos, Habilidades e Atitudes para a atuação do bibliotecário na indústria (Quadro 1).

Como exposto, boa parte dos conhecimentos podem ser aprendidos durante a formação do profissional no âmbito da graduação, como capacidades de identificação e uso das fontes de informação, os processos relacionados à gestão e seus fluxos, tanto com relação às estruturas e funções organizacionais, quanto de gestão da informação. Como exemplo, é possível citar as disciplinas de Teoria Geral de Administração, Organização e métodos, e Planejamento de Unidades de Informação. Ao mesmo tempo, outras exigências foram identificadas, como o domínio de outro idioma, o domínio das TICs, e alto nível de conhecimento sobre o contexto industrial, que são conhecimentos que podem ser adquiridos por meio de cursos de especialização e de formação avançada, ou seja, pela educação continuada. A ALA (2009) já sinalizava que o bibliotecário deve possuir conhecimento especializado na sua área de atuação.

Quanto às habilidades identificadas na literatura, observa-se que as disciplinas técnicas aprendidas durante a graduação dão suporte ao processo, como Serviço de Referência e Informação, que auxilia o bibliotecário no processo de negociação com o usuário, entre a sua demanda e a oferta de informação, permite ao bibliotecário a agilidade para a identificação da informação necessária, visto que por meio da solicitação de determinada informação feita pelo usuário, o bibliotecário consegue identificar de qual informação o usuário necessita no momento. As disciplinas Representação Descritiva de Documentos, Representação Temática e Análise da Informação também dão suporte às habilidades, viabilizando a recuperação de informações para utilizá-las no futuro. 


\begin{tabular}{|l|l|}
\hline Conhecimentos (saber) & Conhecer a gestão documental dentro da indústria \\
& Conhecer as rotinas administrativas \\
& Conhecer os fluxos informacionais da indústria \\
& (Ex.: Sistemas de Gestão da -informação; Gestão Eletrônica de \\
& Documentos, etc.) \\
& Dominar outro idioma \\
& Saber analisar e avaliar as informações pertinentes e relevantes \\
& Saber buscar e selecionar a informação em diferentes fontes de \\
& informação \\
& Saber disseminar a informação utilizando os meios disponíveis e \\
& adequados \\
& Saber usar a informação para solucionar problemas \\
& Ter um nível de conhecimento elevado sobre o contexto de atuação \\
\hline Habilidades (saber fazer) & Avaliar o impacto da informação, dentro da instituição \\
& Possuir habilidade para a solução de problemas \\
& Preservar a informação, para usá-la no futuro \\
& Ter agilidade para a identificação da informação necessária \\
& Ter capacidade de comunicação oral e escrita \\
& Ter capacidade de decisão \\
& Ter capacidade de negociação \\
& Ter capacidade de trabalhar em equipe \\
& Ter visão global do setor industrial \\
\hline Atitudes (saber ser/querer fazer & Aprimorar qualificações, por meio de educação continuada \\
& Perceber as necessidades de informação dos colaboradores \\
& Ser comunicativo \\
& Ser constantemente atualizado \\
& Ser criativo \\
& Ser crítico \\
\hline & Ser ético \\
& Ser flexível às mudanças \\
& Ser proativo \\
& Usar a informação para vantagem competitiva \\
\hline
\end{tabular}

Quadro 1. Dimensões da competência

Quanto às atitudes, as quais demonstram características comportamentais do bibliotecário, sendo aspectos inerentes à pessoa. Amaral et al. (2008) afirmam que as competências são importantes para um bom desempenho em suas atividades. Damásio e Longo (2002, p.25) também sinalizam a importância das competências: "[...] parece imprescindível que os bibliotecários se utilizem de habilidades e competências deles exigida, para utilizar como parâmetro principal para seguir, pois, elas formam a base para a sobrevivência contínua e o crescimento deste profissional na era da informação".

Sendo assim, os conhecimentos, habilidades e atitudes encontrados na literatura norteiam atuação do bibliotecário na indústria. Adicionalmente, buscou-se conhecer mais sobre essas competências na prática. Na entrevista exploratória junto a um bibliotecário, ficou explicitado que a indústria não tinha conhecimento sobre o potencial de atuação do bibliotecário. Ressalta-se que a atuação ocorreu no ano 2000, em que o profissional foi contratado unicamente por seus conhecimentos sobre normas técnicas, como relatado no trecho a seguir:

[...] eles queriam um profissional que soubesse controlar a documentação técnica, como funciona o requisito 4.2, 4.3 da norma. Eles precisavam de uma pessoa que soubesse gerenciar esses requisitos. Existem pessoas de outras áreas do mercado que conseguem fazer isso, mas o bibliotecário tem uma visão melhor da coisa, ele consegue ter uma visão mais ampla da coisa, das necessidades dos setores, da documentação, de controlar revisões [...] (Bibliotecário 1)

Isso coaduna com o que afirmam Damásio e Longo (2002, p.2) a respeito dos profissionais que realizam o gerenciamento de informações nas organizações: "Esses profissionais são contratados pelas empresas, independente de sua formação profissional. Podem ser: engenheiros, administradores, bibliotecários e outros. São escolhidos pela importância de suas habilidades e competências em gerenciar informação, para o bom funcionamento da indústria".

No caso citado, a atuação na indústria estava relacionada à documentação técnica, gestão da qualidade, certificação da ISO 9000 e auditorias. No que tange às competências necessárias ao bibliotecário industrial, destacou-se a capacidade de:

[...] analisar o ambiente como um todo (visão holística), dominar as tecnologias do momento, 
comunicação interpessoal, feedback constante, senso de organização, conhecer a empresa e as pessoas que fazem a empresa, ser curioso, saber ouvir, ser proativo e estar sempre pronto a aprender mais, saber onde está a informação, dominar as ferramentas, se atualizar constantemente e fazer marketing pessoal (Bibliotecário 1).

Na ocasião da entrevista, também se questionou quais foram as disciplinas do curso de Biblioteconomia que mais o prepararam para atuar neste ambiente informacional, sendo citadas: "Serviço de referência, Classificação, Geração e Uso de Banco de Dados, Lógica. Na faculdade nós aprendemos as técnicas. Onde você estiver vai ter informação. Se você não tiver ela organizada não vai oportunizar a geração de conhecimento." (Bibliotecário 1).

Além das disciplinas, outros elementos complementares como proatividade, comunicação interpessoal, saber onde está a informação, dominar as ferramentas e atualização constante, que se assemelham às competências identificadas e expostas anteriormente (Quadro 1).

Na ambiência da indústria, como resultados das duas entrevistas realizadas com o Gestor de RH e um colaborador, os quais serão denominados como Respondente 1 e Respondente 2, ratifica que estes sujeitos têm conhecimento sobre a formação de profissionais da informação na UFAM. Foi perguntado aos respondentes em qual setor da indústria os profissionais da informação poderiam atuar, sendo citado o Sistema de Gestão e o setor de Gestão Integrada:

Nossa empresa não possui uma sistemática para controlar e organizar informações e documentos internos, e um profissional da área seria necessário para implementação dessa sistemática, principalmente na organização de documentos nos arquivos, pois não seguem uma metodologia adequada, são armazenados aleatoriamente. Bem como, temos internamente um setor de Gestão Integrada, responsável pelo controle de documentos e procedimentos relacionados à qualidade (ISO 9001), meio ambiente (ISO 14001) e segurança do trabalho (ISO 45001), e um profissional da área poderia ser de grande relevância para a elaboração de procedimentos e controle de registros e documentos (Respondente 2).

A fala reconhece e reforça a oportunidade de trabalho para os profissionais da informação no setor industrial. Também buscou-se verificar o grau de concordância dos respondentes (Figura 2) com as competências identificadas na literatura, de forma a constatar a concepção destes sobre as competências do bibliotecário industrial, seguidamente apresentados por meio do CHA:

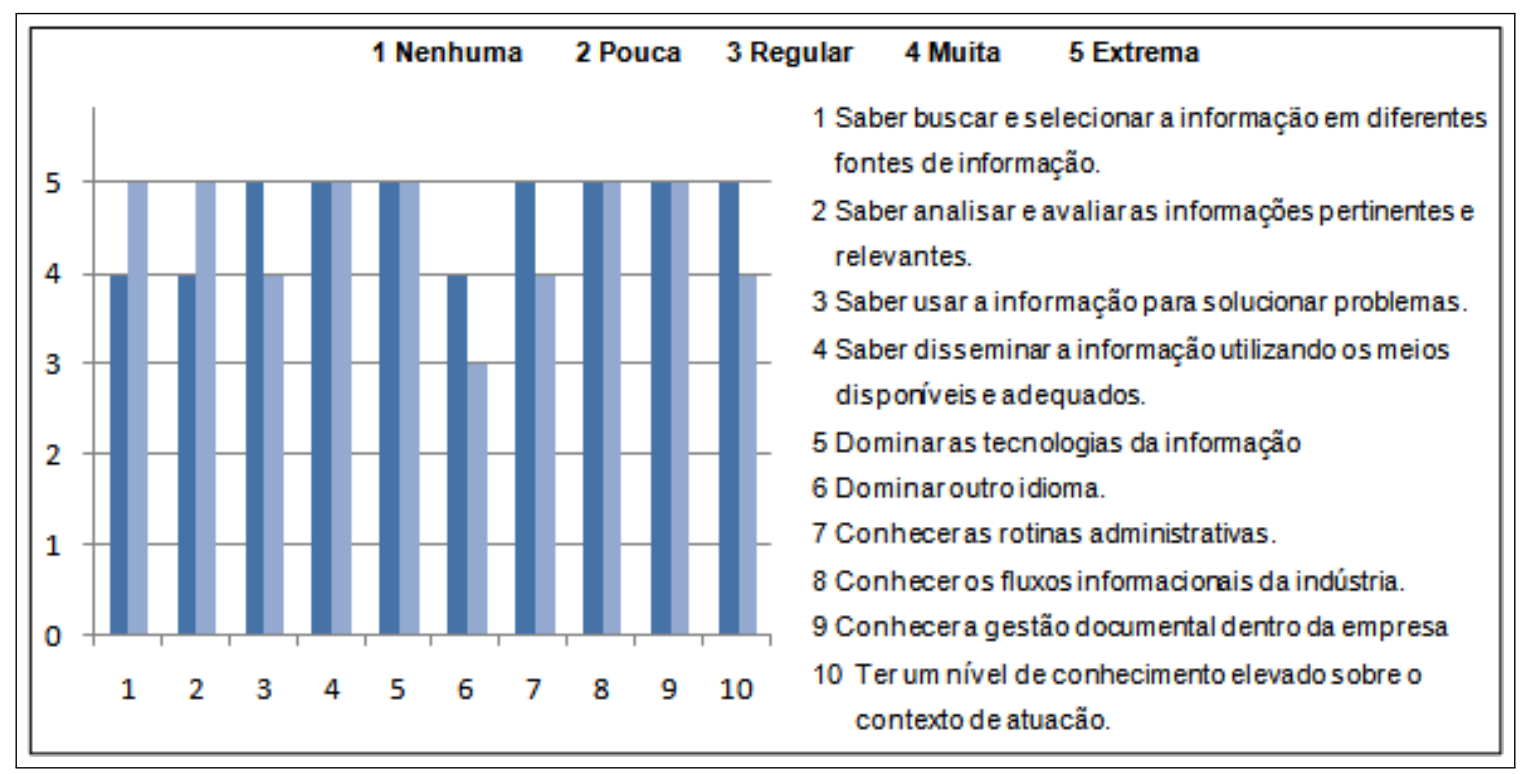

Figura 2. Conhecimentos

Observa-se que é alto grau de concordância quanto aos conhecimentos mapeados na literatura. Principalmente aqueles relacionados a: Saber disseminar a informação utilizando os meios disponíveis e adequados; Dominar as tecnologias da informação; Conhecer os fluxos informacionais da indústria, que, conforme Silva (2016, p.310) "O fluxo da informação é compreendido como parte integrante do processo de comunicação"; Conhecer a gestão documental dentro da empresa. 


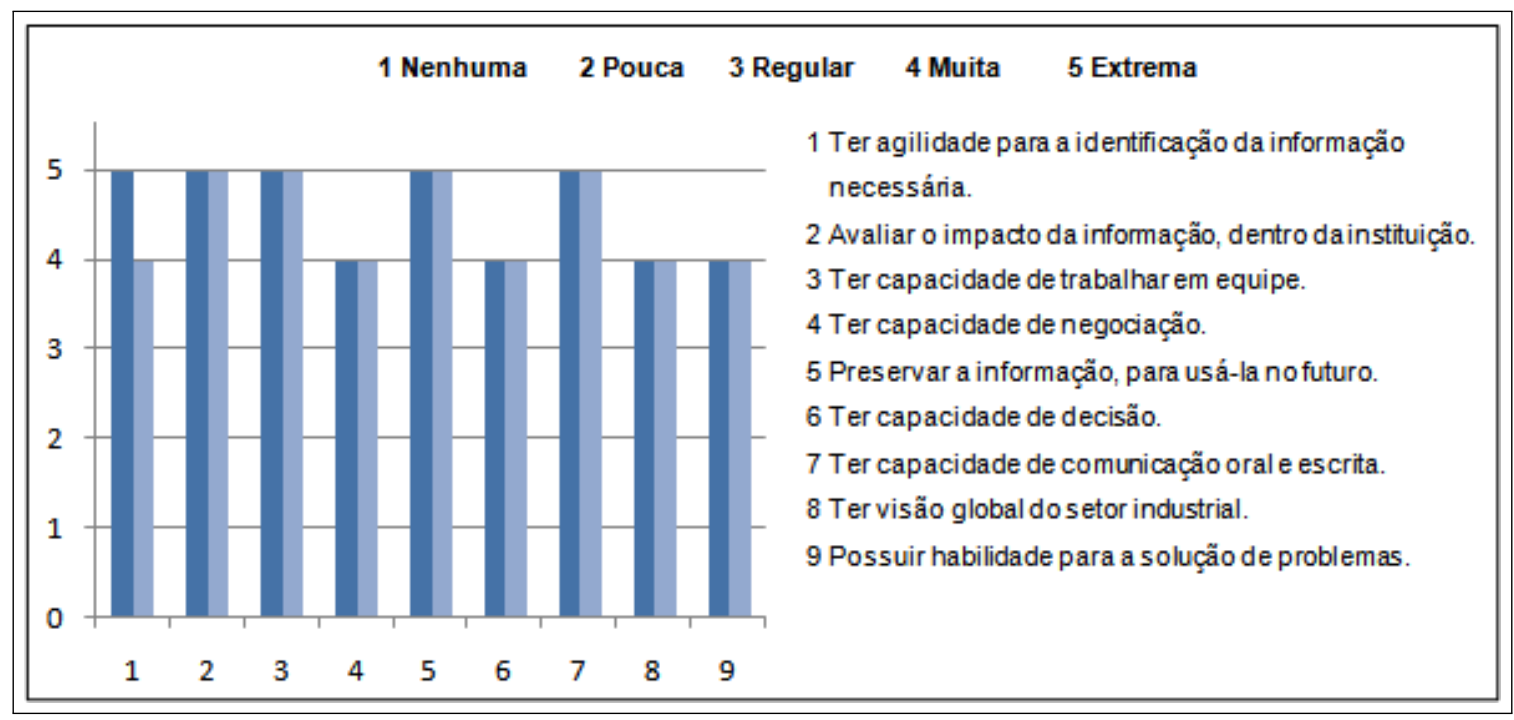

Figura 3. Habilidades

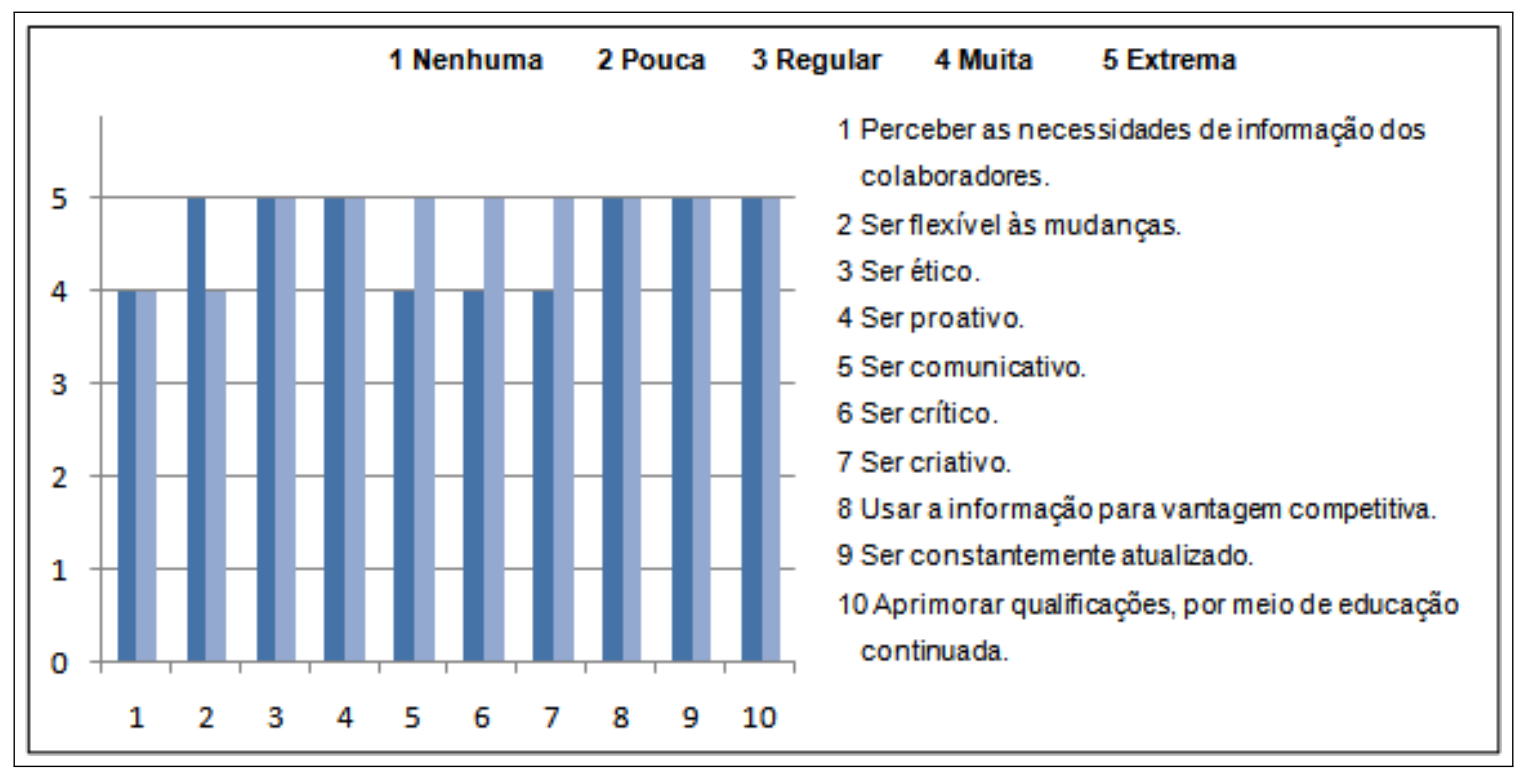

Figura 4. Atitudes

Com relação às habilidades (Figura 3), houve total concordância entre os respondentes que ter capacidade de: Avaliar o impacto da informação dentro da instituição, que, como já mencionado, relaciona-se com a ética; Trabalhar em equipe; Preservar a informação para usá-la no futuro e ter capacidade de comunicação oral e escrita, são aspectos de extrema importância para a indústria.

No que se refere às atitudes (Figura 4), a proatividade e ética são altamente reconhecidas. A proatividade está relacionada tanto a ação na indústria quanto na busca de educação continuada e aprimoramento de qualificação. A ética, que neste caso, se relaciona com o manuseio de informações estratégicas para que se mantenham seguras. Damasio e Longo $(2002$, p.6) destacam que "A questão de aprimoramento profissional se caracteriza principalmente pela multidisciplinariedade desta área, exigindo conhecimentos diferenciados, muitas vezes migrados de diversos cursos e áreas". Ademais, ser criativo também é uma característica importante para a atuação do bibliotecário na indústria. Sobre isso, Jerônimo (2015, p.17) evidencia que "O profissional que adota a criatividade e a inovação em suas atividades aumenta sua empregabilidade no mercado, abre espaço para novos negócios, além de se destacar em sua área de atuação".

Até aqui foram apresentados os resultados inerentes à revisão de literatura e entrevistas, sabe-se que os resultados obtidos nas entrevistas não representam o universo das indústrias do Pólo Industrial de Manaus, mas foram relevantes para se ter um panorama das competências do bibliotecário industrial. O mapeamento das competências (literatura e campo) distribuídas em CHA foram levadas para bibliotecários e professores, ambos especialistas na temática, com vistas a avaliar o grau de concordância destes em relação a estas competências (Figuras 5, 6 e 7).

A Figura 5 mostra que as concordâncias majoritárias estão relacionadas a conhecimentos sobre o processo de gestão da informação (como saber buscar e selecionar a informação em diferentes fontes de informação, usar a 
informação para solucionar problemas), seus fluxos, adicionadas ao domínio das tecnologias de informação.

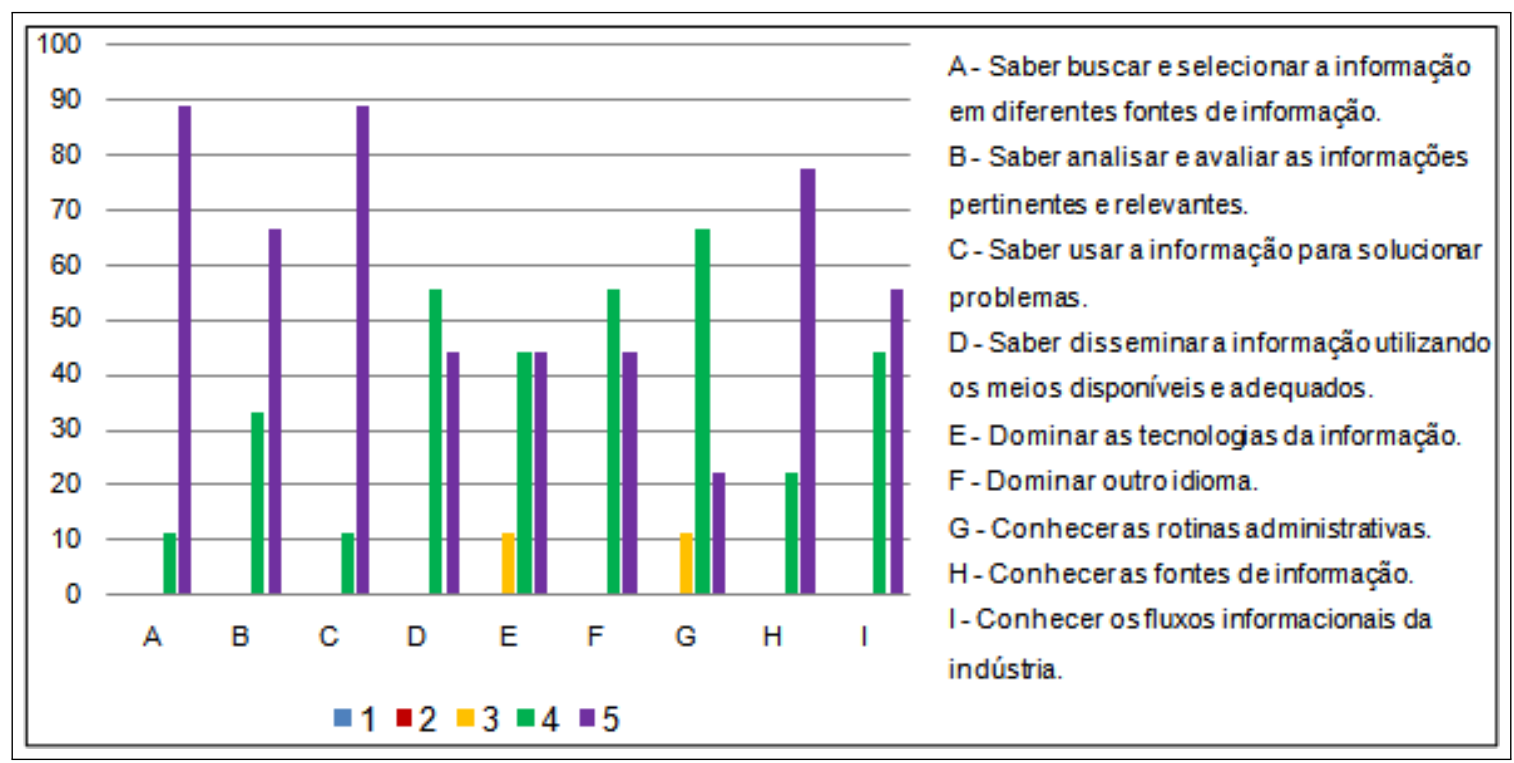

Figura 5. Validação dos conhecimentos

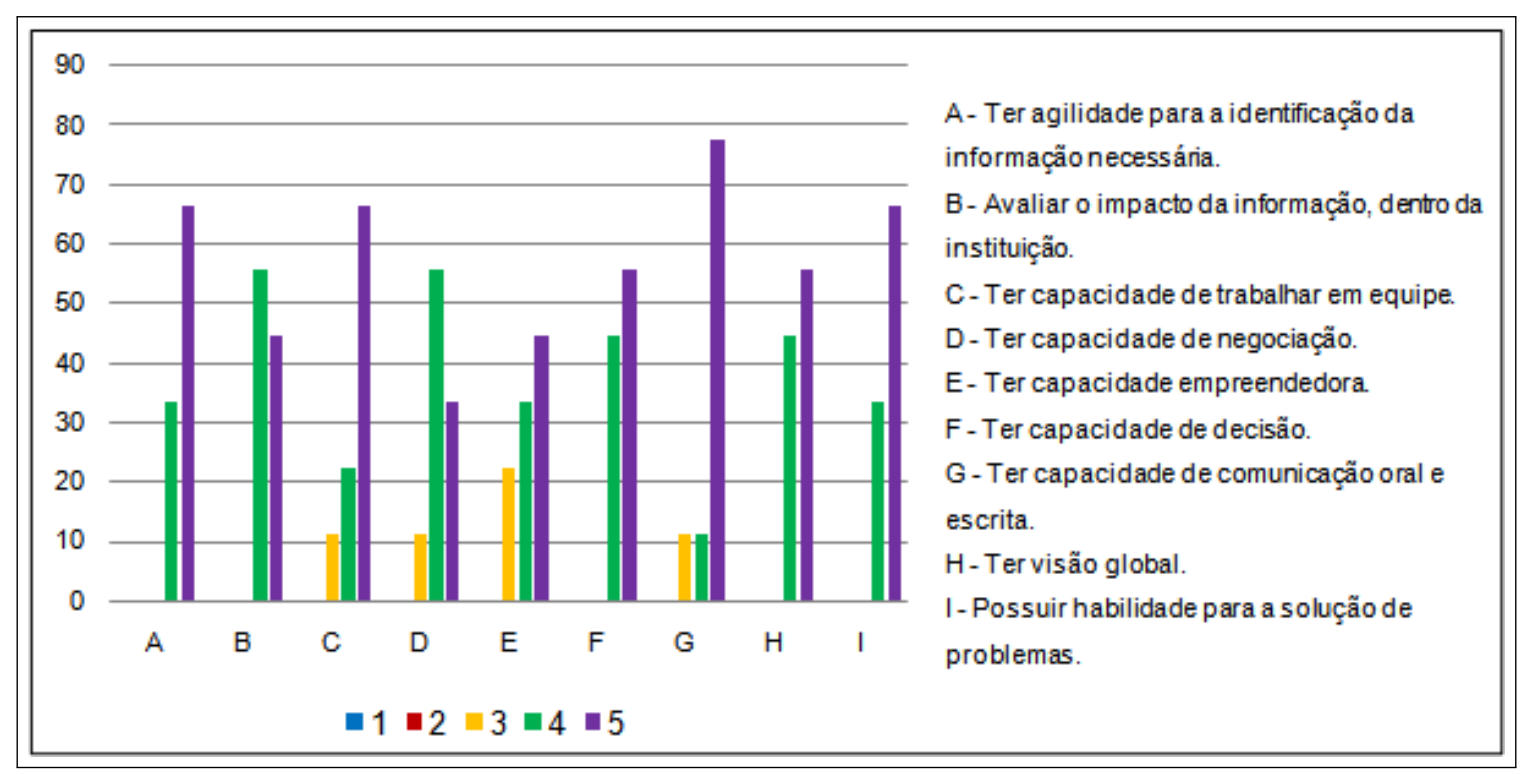

Figura 6. Validação das habilidades

Com relação às habilidades (Figura 6), as concordâncias majoritárias estão relacionadas ao processo de comunicação, agilidade na identificação da informação estratégica, na solução de problemas e no trabalho em equipe. Sobre isso, destacou-se que:

Deveria partir do pressuposto que o profissional bibliotecário possui papel fundamental em toda a cadeia produtiva que depende da informação para seu bom funcionamento. Tendo ele papel fundamental para a resolução de problemas informacionais a fim de atender as necessidades de informação da organização. Para tal o profissional deve ter uma postura profissional que se adeque às demandas da indústria tendo ele que absorver novos conhecimentos que, na grande maioria das vezes, não são ensinados no curso de graduação. (Bibliotecário 2) 


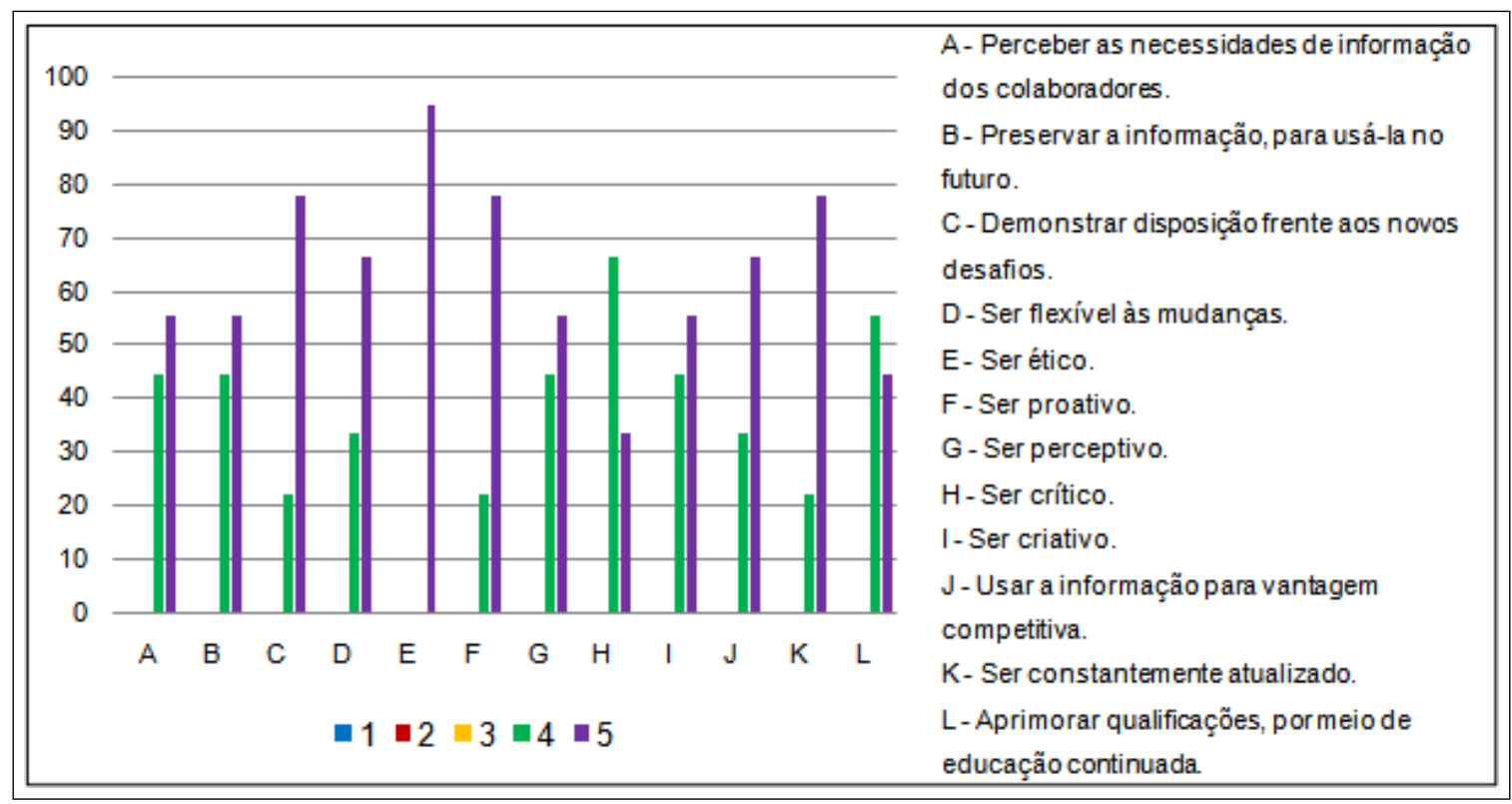

Figura 7. Validação das habilidades

Com relação às atitudes (Figura 7), aquelas que são subjetivas, assim como sinalizado nos resultados do campo, para os especialistas a ética também é uma atitude essencial. Além da proatividade, que vem sendo reforçada pelos participantes da pesquisa.

O bibliotecário que atua na indústria/empresas deve ter a percepção da diferença em sua atuação, não sendo a mesma que em unidades de informação (como bibliotecas, por exemplo). Nesse ambiente de mercado o desenvolvimento de conhecimentos específicos, a pró-atividade e a atualização constantes serão grandes diferenciais no sucesso do trabalho do bibliotecário e na percepção, por parte dos outros profissionais, da importância de sua atuação. (Bibliotecário 3).

Sobre as competências propostas para a atuação do bibliotecário na indústria, o Bibliotecário 4 esclarece:

Acredito que de forma geral todas as competências (conhecimentos, habilidades e atitudes) foram incorporadas nas questões do questionário. Ele precisa dominar as novas tecnologias, estar sempre se atualizando quanto às novas ferramentas (softwares e hardwares), dominar mais de um idioma, principalmente o inglês, precisa ser proativo e dinâmico. Acho que um dos locais mais difíceis de conseguir emprego para o bibliotecário atualmente é a indústria, vejo poucos colegas atuarem nesse setor, talvez não conheça nenhum muito próximo. De um lado eu vejo profissionais recém formados reclamando que não há vagas de trabalho e de outro eu vejo empregadores reclamando que não há profissionais adequadamente qualificados para a vaga, pelo menos essa é a realidade em Florianópolis. Então, essas competências com certeza perpassam a formação acadêmica, pois, atitudes são inerentes ao ser humano, não podem ser moldadas. Mesmo conhecimentos e habilidades para serem dominados com maestria precisam de tempo e dedicação que muitas vezes não são suficientes diante de tantas disciplinas que os alunos fazem os mesmo tempo dentro de um semestre. Nos formamos e nos tornamos generalistas e não especialistas. A solução talvez seria uma pós-graduação nesta área (especialização EaD), por um curto período de tempo (mediante necessidade x demanda) para enfocar nessas habilidades e conhecimentos. (Bibliotecário 4).

Para encerrar os comentários cunhados pelos especialistas, especificamente sobre o rol de competências apresentados, destacou-se que: "Os pontos reunidos neste formulário dão base para um profissional competente e capaz no desempenho de buscas e entregas com excelência ao mercado da indústria." (Bibliotecário 5).

\section{CONCLUSÃO}

A pesquisa evidencia as primeiras aproximações sobre as competências de atuação do bibliotecário industrial. Reforça-se a necessidade do profissional buscar competências adicionais que o capacitem para desempenhar suas funções de forma eficaz e eficiente no contexto da indústria, levando sempre em consideração as necessidades e particularidades desse ambiente. Considerando que nem todas as competências identificadas serão adquiridas somente no processo formativo (graduação em Biblioteconomia), cabe ao profissional se aperfeiçoar por meio da educação continuada.

Tanto na revisão de literatura (ainda incipiente) quanto na pesquisa de campo, encontrou-se competências que servem como parâmetro para a atuação do bibliotecário na indústria, o qual foi designado como bibliotecário 
industrial. Sem esgotar o CHA necessário para uma atuação exitosa na indústria, destaca-se que, para além dos conhecimentos sobre gestão, habilidades relacionadas às capacidades de comunicação e trabalho em equipe, ser ético e proativo foram atitudes altamente sinalizadas como relevantes pela pesquisa.

Espera-se que este seja um levantamento útil para sinalizar que há espaço para o bibliotecário na indústria, embora seja um espaço emergente não ocupado, sobretudo pelo potencial deste profissional para contribuir com as atividades industriais. Sendo assim, buscou-se também, por meio deste artigo, dar visibilidade para a inserção do bibliotecário neste espaço, constituindo um benefício tanto para a indústria quanto para o profissional da informação e a sociedade.

Adicionalmente, vale evidenciar, como já sinalizado por Ottonicar e Valentim (2019), que as universidades têm o papel de formar profissionais que enfrentem as questões tecnológicas, sociais, políticas e econômicas no contexto em que atuam, e que estes indivíduos possam se sentir parte das organizações onde atuam, como destacou Dutra (2017), para que se sintam confortáveis com os entregáveis à organização, tendo maiores possibilidades de realização e felicidade.

Sugere-se a continuidade na investigação sobre a atuação do profissional da informação na indústria, por meio da abordagem aprofundada de outros aspectos referentes a esta atuação, como as fontes de informação da indústria e a caracterização do usuário no setor industrial, em diferentes portes. Outra possibilidade de continuidade da pesquisa é verificar, com base na perspectiva de Dutra (2017), as competências na indústria a partir da capacidade de entrega e realizações pessoais dos colaboradores (neste caso, da pessoa bibliotecária). Adicionalmente, no que tange aos novos espaços de atuação, sugere-se a investigação de competências por meio do CHA em outros espaços emergentes em que o(a) bibliotecário(a) pode se inserir como na Biblioteconomia Clínica, como as Emissoras de TV. 


\section{REFERÊNCIAS}

Amaral, R. M., Garcia, L. G., Faria, L. I. L. d., \& Aliprandini, D. H. (2008). Modelo para o mapeamento de competências em equipes de inteligência competitiva. Ciência da Informação, 37, 7-19. Recuperado de https://www.scielo.br/pdf/ ci/v37n2/a01v37n2.pdf doi: 10.18225/ci.inf..v37i2.1208

American Library Association (ALA). (2009). Ala's core competences of librarianship. S. 1.: ALA.

Amorim, I. R. d., \& Amaral, R. M. d. (2011). Mapeamento de competências em bibliotecas e unidades de informação. Perspectivas em Ciência da Informação, 16, 2-16.

Battaglia, M. d. G. B. (1999). A inteligência competitiva modelando o sistema de informação de clientes-finep. Ciência da Informação, 28, 200-214.

Bexon, M., Stephens, D., \& Pritchett, C. (2002). Competitive intelligence: a career opportunity for the information professional in industry. Journal of librarianship and information science, 34 (4), 187-196.

Cazella, S. C., Behar, P., Schneider, D., da Silva, K. K., \& Freitas, R. (2012). Desenvolvendo um sistema de recomendação de objetos de aprendizagem baseado em competências para a educação: relato de experiências. In Brazilian symposium on computers in education (simpósio brasileiro de informática na educação-sbie) (v. 23).

Classificação brasileira de ocupações. (2002). Ministério do Trabalho. Recuperado de http://www.mtecbo.gov.br/ cbosite/pages/home.jsf

Damasio, E., \& Longo, R. M. J. (2002). O profissional da informação na indústria: habilidades e competências.

de Biblioteconomia, C. F. (2018). ,resolução $c f b \quad n^{o}$ 207/2018. Sistema CFB/CRB.

Dutra, J. S. (2017). Competências: conceitos, instrumentos e experiências.

Fyre, J. J. (1973). Características de um serviço de informação para a indústria. Revista da Escola de Biblioteconomia da UFMG, 2(2), 176-195.

Hansen, M. E., \& Curtis, J. M. (1998). Challenges and benefits of chemical information service in industry. Science E) Technology Libraries, 16(3-4), 209-228.

Jerônimo, V., et al. (2015). Bibliotecários criativos: práticas inovadoras no contexto da atuação profissional.

Orelo, E. R. M., \& da Cunha, M. F. V. (2013). O bibliotecário e a competência informacional. Informação $\mathscr{G}$ Sociedade, 23(2).

Ottonicar, S. L. C., \& Valentim, M. L. P. (2019). A competência em informação no contexto do trabalho: uma revisão sistemática da literatura voltada para industria 4.0. Encontros Bibli: revista eletrônica de biblioteconomia e ciência da informação, 24(56), 1-21.

Pinheiro, M. G. (1991). Informação para a indústria. Ciência da Informação, 20(1).

Pintro, S., Rados, G. J. V., \& Inomata, D. O. (2017). Competências do bibliotecário no processo de referência educativo de bibliotecas universitárias. Revista ACB: Biblioteconomia em Santa Catarina, 22(2), 329-342.

Pizarro, D. C. (2011, mar. ). Ética profissional do bibliotecário atuante no segmento empresarial de santa catarina | professional ethics of librarians active in the business segment of santa catarina. Liinc em Revista, 7(1). Recuperado de https://doi.org/10.18617/liinc.v7i1.411 doi: 10.18617/li- inc.v7i1.411

Silva, E. V. d., Silva, A. J. R. P. d., Rosemberg, D. S., \& Carvalho, I. C. L. (2008). O perfil dos gestores de informação para a indústria capixaba. Ciência da Informação, 37, 7384.

Silva, M. F. d. (2016). Processo de comunicação no ambiente interno de uma indústria: compreensões a partir da análise de conteúdo. Informação $\mathscr{E}$ Informação; v. 21, n. 1 (2016); 306-323, 24 (2), 323-306.

Valls, V. (2019). O bibliotecário fora da biblioteca. , 12(75), $3-4$.

Como citar este artigo (APA):

(2021). Mapeamento de competências do bibliotecário para uma atuação na indústria. AtoZ: novas práticas em informação e conhecimento, 10(3), 1 - 12. Recuperado de: http://dx.doi.org/10.5380/atoz.v10i3 .65779 